\title{
Barrett's esophagus: Is it all that bad?
}

\author{
GNJ Tytgat MD PhD
}

\begin{abstract}
GNJ Tytgat. Barrett's esophagus: Is it all that bad? Can J Gastroenterol 1999;13(5):385-388. An alarmingly rapid rise in the number of adenocarcinomas at the level of the gastroesophageal junction and distal esophagus has been noted over the past two decades. Intestinal metaplasia is considered to be the main precursor lesion for such adenocarcinomas. Given the low five-year survival rate in patients with advanced esophageal cancer, strategies for early detection have been developed. Because superficial cancers only rarely cause symptoms, detection of cancer at such an early curable state can only be achieved through surveillance of patients at risk. Therefore, implementation of an endoscopic surveillance program for patients in whom intestinal metaplasia has been detected in the distal esophagus or at the esophagogastric junction seems to be a reasonable option.
\end{abstract}

Key Words: Adenocarcinoma; Barrett's esophagus; Endoscopy; Intestinal metaplasia

\section{L'œsophage de Barrett : est-ce si grave?}

RÉSUMÉ : Depuis deux décennies, on observe une augmentation alarmante du nombre d'adénocarcinomes au niveau de la jonction gastro-œsophagienne et de l'œsophage distal. La métaplasie intestinale est considérée comme la principale lésion précurseure de ces adénocarcinomes. Compte tenu du faible taux de survie après cinq ans chez les patients atteints d'un cancer de l'œsophage avancé, des stratégies de dépistage précoce ont été mises au point. Compte tenu que les cancers superficiels ne provoquent que rarement des symptômes, le dépistage du cancer à un stade où la maladie est curable, ne s'obtient que par la surveillance des patients à risque. Par conséquent, la mise en place de programmes épidémiologiques endoscopiques pour les patients chez qui la métaplasie intestinale a été décelée dans l'œsophage distal ou à la jonction œsophago-gastrique semble une option envisageable.
$\mathrm{A}_{\mathrm{n}}^{\mathrm{n}}$ $\mathrm{n}$ alarmingly rapid rise in the number of adenocarcinomas at the level of the gastroesophageal junction and distal esophagus has been noted over the past two decades $(1,2)$. Intestinal metaplasia is considered to be the main precursor lesion for such adenocarcinomas. The prevalence of intestinal metaplasia at the level of the cardia, or (ultra) short (less than 2 to $3 \mathrm{~cm}$ ) or long (greater than 2 to $3 \mathrm{~cm}$ ) segments of columnar metaplasia in the distal esophagus in the general population is unknown but may be substantial. Columnar metaplasia may be detected in $10 \%$ to $15 \%$ of patients evaluated endoscopically for reflux symptoms $(3,4)$.

The risk of malignancy in esophageal columnar metapla- sia (Barrett's esophagus) is thought to be 30 - to 120 -fold greater than that in the general population $(5,6-9)$. Given the low five-year survival rate in patients with advanced esophageal cancer, strategies for early detection have been developed. The rational for such strategies derives from the fact that patients who undergo surgery for superficial lesions that are limited to the mucosa or submucosa have a much more favourable prognosis, with a $60 \%$ to $100 \%$ five-year recovery rate (10-12). Because superficial cancers only rarely cause symptoms, detection of cancer at such an early curable state can only be achieved through surveillance of patients at risk. Therefore, implementation of an endoscopic surveillance

Academic Medical Center, Department of Gastroenterology and Hepatology, Amsterdam, The Netherlands

Correspondence: Dr GNJ Tytgat, Academic Medical Center, Department of Gastroenterology and Hepatalogy, Meibergdreef 9 1105 AZ, Amsterdam, The Netherlands. Telephone 31-20-566-9111, fax 31-20-566-4440, e-mail g.n.tytgat@amc.uva.nl 
program for patients in whom intestinal metaplasia has been detected in the distal esophagus or at the esophagogastric junction seems to be a reasonable option.

\section{ENDOSCOPIC DETECTION OF COLUMNAR METAPLASIA}

The proximal extent of the gastric folds provides a reliable endoscopic landmark to identify the junction between the esophagus and stomach (13-15). Any length of pinkish mucosa in the lower esophagus above the proximal extent of the gastric folds that contains intestinalized mucosa or intestinal metaplasia on biopsy qualifies for a diagnosis of esophageal columnar metaplasia or Barrett's esophagus, regardless of the length of this segment. Histology is, therefore, essential to diagnose columnar metaplasia when only short, pink tongues are present in the distal esophagus. The combined hematoxylin and eosin-alcian blue $\mathrm{pH} 2.5$ stain is invaluable for the histologic definition of intestinal-type mucosa (1618; Personal communication, W Polkowski et al). A short segment esophageal columnar metaplasia is most often arbitrarily defined as columnar metaplasia less than 2 to $3 \mathrm{~cm}$ in length above the esophagogastric junction (19-21). In the case of long segment Barrett's esophagus, the length of the metaplastic segment extends beyond 2 to $3 \mathrm{~cm}$. Whether small tongues or patches of columnar mucosa with evidence of intestinal metaplasia in the vicinity of the squamocolumnar junction correspond to ultrashort segments of Barretttype columnar metaplasia or intestinal metaplasia of the cardia in patients with a somewhat irregular squamocolumnar junction is impossible to tell from an endoscopic point of view, because the histological appearance is identical.

\section{INTESTINAL METAPLASIA- DYSPLASIA-CARCINOMA SEQUENCE}

Many studies have shown that malignant progression occurs through stages of increasing severity of dysplasia $(7,18$, 22-26). The rate at which low grade dysplasia develops into high grade dysplasia and ultimately cancer is highly variable. High grade dysplasia is an ominous sign and indicates impending malignancy within a short period of time. Commonly, malignant foci are already present but are not discovered when high grade dysplasia is detectable in biopsies.

Ideally disease should be detected at the stage of high grade dysplasia, before overt or occult malignancy has developed.

\section{ENDOSCOPIC DETECTION OF DYSPLASIA}

The endoscopic detection of dysplasia is problematic. In general, no peculiar endoscopic features permit a distinction between dysplastic and nondysplastic mucosae.

Exceptionally dysplastic areas may be suspected when the mucosa is somewhat more whitish, although usually such more whitish plaques consist of patches of nondysplastic mucosal thickening. Equally exceptional is the detection of dysplasia in areas that disclose a somewhat peculiar vascularity or have an inflamed appearance. Finally, dysplasia may also be suspected in areas with conspicuous villiform appearance.
It has been claimed that toluidine blue staining may be helpful in detecting areas of high grade dysplasia, suitable for targeted biopsy, but this is rather questionable (27). In contrast, methylene blue-directed biopsy may improve the detection of intestinal metaplasia and by doing may also detect dysplasia, if present (28).

\section{HISTOLOGIC DETECTION OF DYSPLASIA}

Usually, dysplasia is detected in random biopsies taken at intervals of 1 to $2 \mathrm{~cm}$ from all quadrants of the metaplastic segment. The use of large calibre biopsy forceps (9 French or $8 \mathrm{~mm}$ open span) is advisable, but this requires an endoscope with a large (greater than $3.5 \mathrm{~mm}$ ) instrumentation channel. In routine practice, biopsies are often taken with standard biopsy forceps, and often only two biopsies are taken from opposite walls at $2 \mathrm{~cm}$ intervals $(29,30)$.

\section{ENDOSCOPIC APPEARANCE OF EARLY MALIGNANCY}

Superficial esophageal cancer is often subdivided in three macroscopic subtypes, according to the differences in height in relation to the noncancerous adjacent mucosa (31). Type 1 is characterized by an elevated or protruded lesion; type 2 is a superficial flat lesion; type 3 corresponds to a depressed or excavated type.

A common appearance is that of a circumscribed polypoid or protruded lesion (type 1). Early malignancy may also appear as a plaque-like lesion in which the cancerous area appears slightly elevated with a granular knobby surface or a circumscribed area of altered pliability or patch of mucosal discoloration (type 2). Superficial cancer can also present as a slightly depressed area with grey erosive spots against a reddish background (type 3). A rather exceptional but most intriguing presentation is 'occult type' cancer where in essence no suspicious endoscopic abnormalities are visible. It should be stressed that multiple biopsies have to be taken at various levels within the columnar segment to establish the spread of the malignancy. If only high grade dysplasia is found, biopsies should be repeated because high grade dysplasia is often associated with superficial malignancy (27,32-35; Personal communication, JW Sandick et al).

\section{CONSEQUENCES OF DETECTION OF HIGH GRADE DYSPLASIA}

When high grade dysplasia is detected, a clinical dilemma is often encountered. In expert centres with a low operative morbidity and mortality for esophageal resection, high grade dysplasia is increasingly regarded as the end point of surveillance for patients who are good surgical risks and who can withstand a major operation (35-39). Other experts advise deferring esophagectomy until proven invasive adenocarcinoma is documented. In the meantime, these experts propose that surveillance should be continued at very short intervals (three months) with strict endoscopic biopsy protocols $(18,40,41)$. It should be stressed that high grade dysplasia has been identified as a predictor of future cancer development. Also, it may indicate the presence of a coexis- 
tent covert invasive adenocarcinoma. A recent collective series of 96 patients who underwent esophagectomy for high grade dysplasia revealed a $41 \%$ incidence of endoscopically undetected adenocarcinoma, with an overall postoperative mortality of 4\% (42). In the study of Van Sandick et al (43), four of six patients with a biopsy diagnosis of high grade dysplasia were identified to have invasive adenocarcinoma in the resection specimen. Such findings emphasize the limitations of the random biopsies in detecting foci of malignancy in such patients. The frequency of finding a coexisting adenocarcinoma is high and, therefore, justifies esophageal resection in patients with an unequivocal diagnosis of high grade dysplasia who are likely to tolerate a major surgical procedure.

\section{COST EFFICACY CONSIDERATIONS}

Although the cost efficacy of surveillance in columnar metaplasia has been questioned by some authors $(44,45)$, two recent studies indicate that the cost of endoscopic surveillance to detect adenocarcinoma in patients with esophageal columnar metaplasia compares quite favourably with the cost of screening mammography to detect early breast cancer $(46,47)$.

A much greater concern is the ultimate lack of evidence that surveillance ultimately reduces the mortality due to esophageal adenocarcinoma. The ideal methodology for the evaluation of the efficacy of surveillance is a randomized trial. Such a trial not only seems impractical in terms of the number of patients needed and the many years of follow-up (48) but also may pose several ethical dilemmas for the physicians who would be asked to withhold a potentially lifesaving procedure from an individual with a premalignant condition. Provenzale et al (49) estimated that, if the annual risk of cancer development in esophageal columnar metaplasia is $1.3 \%$, then a randomized trial designed to show an efficacy of endoscopic surveillance would require 5000 patients to be followed for 10 years. For patients with short segment intestinal metaplasia at the gastroesophageal junction, whose annual cancer risk is substantially less than the $1.3 \%$, even larger numbers of patients and longer duration of follow-up would be required for a study to show a significant benefit. It is, therefore, unlikely that a randomized study will ever be performed to prove the value of cancer surveillance in columnar metaplasia. The logistics of conducting such enormous long term studies are truly daunting and the ethics highly questionable.

\section{EFFECT OF SURVEILLANCE ON CANCER MORTALITY RATES}

Indirect proof of efficacy may be derived by evaluating the effect of surveillance on cancer mortality rates. The method most commonly used compares the outcomes of surveillance-detected cancer cases with those of symptomdiagnosed cases.

Several studies have indicated that endoscopic biopsy surveillance may provide a beneficial effect on resectability and mortality from cancer in esophageal columnar metaplasia $(46,50,51$; personal communication). Patients who have undergone some form of endoscopic surveillance were operated on at significantly earlier stages of their disease with a subsequent survival advantage over patients who were not part of a surveillance program.

However, such nonrandomized types of evaluation harbour a number of pitfalls $(42,52)$. A first pitfall is selection bias. Patients undergoing regular surveillance tend to be health conscious and may be the ones who would have presented with early stage cancer even if their disease were diagnosed because of symptoms. A second pitfall is lead-time bias, which operates in all screening and surveillance programs (53). An observed survival benefit may be due only to the advancement of the diagnosis of cancer in time and not to the postponement of death. A third pitfall is length bias (54). Length bias occurs because screening programs are more likely to detect slow growing lesions, with a favourable prognosis, than lesions with a more aggressive nature and relatively more unfavourable prognosis.

The stage distribution and the duration of survival in the surveillance group of our patients may partly reflect lead time and length bias for cancer in Barrett's esophagus. Despite such shortcomings of evaluating cancer surveillance in such patients, efforts to do so should continue in order to clarify factors that affect outcome.

\section{CONCLUSIONS}

Endoscopic biopsy surveillance of patients with high grade dysplasia or early cancer in esophageal columnar metaplasia allows the detection of cancer at an early, curable stage. None of the patients in surveillance groups had advanced stage cancer compared with $50 \%$ to $60 \%$ of patients in nonsurveillance groups who had stage 3 or 4 tumours. Patients from the surveillance group appeared to have a significant survival advantage after resection. The striking difference in survival strongly suggests that a long term reduction in cancer mortality by widespread surveillance of patients with columnar metaplasia is indeed possible.

\section{REFERENCES}

1. Blot WJ, Devesa SS, Kneller RW, Fraumeni JF Jr. Rising incidence of adenocarcinoma of the esophagus and gastric cardia. JAMA 1991;265:1287-9.

2. Pera M, Cameron AJ, Trastek VF, et al. Increasing incidence of adenocarcinoma of the esophagus and esophagogastric junction. Gastroenterology 1993;104:510-3.

3. Winters C, Spurling TJ, Chobanian SJ, et al. Barrrett's esophagus. A prevalent, occult complication of gastroesophageal reflux disease. Gastroenterology 1987;92:118-24.

4. Stein HJ, Barlow AP, DeMeester TR, Hinder RA. Complications of gastroesophageal reflux disease. Role of the lower esophageal sphincter, esophageal acid and acid/alkaline exposure, and duodenogastric reflux. Ann Surg 1992;216:35-43.

5. Spechler SJ, Robbins AH, Rubins HB, et al. Adenocarcinoma and Barrett's esophagus. An overrated risk? Gastroenterology 1984;87:927-33.

6. Cameron AJ, Ott BJ, Payne WS. The incidence of adenocarcinoma in columnar-lined (Barrett's) esophagus. N Engl J Med 1985;313:857-9.

7. Hameeteman W, Tytgat GNJ, Houthoff HJ, Van Den Tweel JG. Barrett's esophagus: development of dysplasia and adenocarcinoma. Gastroenterology 1989;96:1249-56. 
8. Williamson WA, Ellis FH Jr, Gibb SP, et al. Barrett's esophagus. Prevalence and incidence of adenocarcinoma. Arch Intern Med 1991;151:2212-6.

9. Iftikhar SY, James PD, Steele RJC, et al. Length of Barrett's oesophagus: an important factor in the development of dysplasia and adenocarcinoma. Gut 1992;33:1155-8.

10. DeMeester TR, Attwood SEA, Smyrk TC, et al. Surgical therapy in Barrett's esophagus. Ann Surg 1990;212:528-40.

11. Menke-Pluymers MBE, Schoute NW, Mulder AH, et al. Outcome of surgical treatment of adenocarcinoma in Barrett's oesophagus. Gut 1992;33:1454-8

12. Lerut T, Coosemans W, Van Raemdonck D, et al. Surgical treatment of Barrett's carcinoma. Correlations between morphologic findings and prognosis. J Thorac Cardiovasc Surg 1994;107:1059-65.

13. Tytgat GNJ, Hameeteman W, Onstenk R, Schotborg R. The spectrum of columnar-lined esophagus - Barrett's esophagus. Endoscopy 1989;21:177-85.

14. McClave SA, Boyce HW, Gottfried MR. Early diagnosis of columnar-lined esophagus: a new endoscopic diagnostic criterion. Gastrointest Endosc 1987;33:413.

15. Tytgat GNJ. Endoscopic diagnosis of columnar-lined esophagus. Motility 1989;7:14-5.

16. Weinstein WM, Ippoliti AF. The diagnosis of Barrett's esophagus: goblets, goblets, goblets. Gastrointest Endosc 1996;44:91-4.

17. Gottfried MR, McCave SA, Boyce HW. Incomplete intestinal metaplasia in the diagnosis of columnar lined esophagus (Barrett's esophagus). Can J Clin Pathol 1989;92:741-6.

18. Haggitt RC. Barrett's esophagus, dysplasia, and adenocarcinoma. Hum Pathol 1994;25:982-93.

19. Johnston MH, Hammond AS, Laskin W, Jones DM. The prevalence and clinical characteristics of short segments of specialized intestinal metaplasia in the distal esophagus on routine endoscopy. Am J Gastroenterol 1996;91:1507-11.

20. Weston AP, Krmpotich P, Makdisi WF, et al. Short segment Barrett's esophagus: Clinical and histological features, associated endoscopic findings, and association with gastric intestinal metaplasia. Am J Gastroenterol 1996;91:981-6.

21. Tytgat GNJ. Endoscopic features of the columnar-lined esophagus. Gastroenterol Clin North Am 1997;26:507-17.

22. Miros M, Kerlin P, Walker N. Only patients with dysplasia progress to adenocarcinoma in Barrett's oesophagus. Gut 1991;32:1441-6.

23. Reid BJ, Blount PL, Rubin CE, et al. Flow-cytometric and histological progression to malignancy in Barrett's esophagus: prospective endoscopic surveillance of a cohort. Gastroenterology 1992;102:1212-9.

24. Polkowski W, Van Lanschot JJB, Ten Kate FJW, et al. The value of p53 and Ki67 as markers for tumour progression in the Barrett's dysplasia-carcinoma sequence. Surg Oncol 1995;4:163-71.

25. Tytgat GNJ, Hameeteman W. The neoplastic potential of columnar-lined (Barrett's) esophagus. World J Surg 1992;16:308-12.

26. Hameeteman W, Tytgat GNJ, Houthoff HJ, Van den Tweel JG. Barrett's esophagus: development of dysplasia and adenocarcinoma. Gastroenterology 1989;96:1249-56.

27. Chobanian SJ, Cattau EL Jr, Winters C Jr, et al. In vivo staining with toluidine blue as an adjunct to the endoscopic detection of Barrett's esophagus. Gastrointest Endosc 1987;33:99.

28. Canto M, Setrakian S, Chak A, Sivak MV Jr. Methylene blue-directed biopsy for improved detection of intestinal metaplasia and dysplasia in Barrett's esophagus: a controlled sequential trial. Gastrointest Endosc 1996;43:332. (Abst 165)

29. Stein HJ. Esophageal cancer: screening and surveillance. Results of a consensus conference held at the VIth world congress of the International Society for Diseases of the Esophagus. Dis Esophagus 1996;9:S3-19.

30. McArdle JE, Lewin KL, Randall G, Weinstein W. Distribution of dysplasias and early invasive carcinoma in Barrett's esophagus. Hum Pathol 1992;23:479-82.

31. Nishimaki T, Hölscher A, Schüler M, et al. Histopathologic characteristics of early adenocarcinoma in Barrett's esophagus. Cancer 1991;68:1731-6.

32. Reid BJ, Weinstein WM, Lewin KJ, et al. Endoscopic biopsy can detect high-grade dysplasia or early adenocarcinoma in Barrett's esophagus without grossly recognizable neoplastic lesions. Gastroenterology 1988;94:81.

33. Reid BJ, Haggitt RC, Rubin CE, et al. Observer variation in the diagnosis of dysplasia in Barrett's esophagus. Hum Pathol 1988;19:166.

34. Streitz JM Jr, Ellis FH Jr, Gibb SP, et al. Adenocarcinoma in Barrett's esophagus. A clinico-pathologic study of 65 cases. Ann Surg 1991;213:122-5.

35. Pera M, Trastek VF, Carpenter HA, et al. Barrett's esophagus with high-grade dysplasia: an indication for esophagectomy? Ann Thorac Surg 1992;54:199-204.

36. Rice TW, Falk GW, Achkar E, Petras RE. Surgical management of high-grade dysplasia in Barrett's esophagus. Am J Gastroenterol 1993;88:1832-6

37. Edwards MJ, Gable DR, Lentsch AB, Richardson JD. The rationale for esophagectomy as the optimal therapy for Barrett's esophagus with high-grade dysplasia. Ann Surg 1996;223:585-91.

38. Altorki NK, Sunagawa M, Little AG, Skinner DB. High-grade dysplasia in the columnar-lined esophagus. Am J Surg 1991;161:97-9.

39. Heitmiller RF, Redmond M, Hamilton SR. Barrett's esophagus with high-grade dysplasia. An indication for prophylactic esophagectomy. Ann Surg 1996;224:66-71.

40. Reid BJ, Weinstein WM, Lewin KJ, et al. Endoscopic biopsy can detect high-grade dysplasia or early adenocarcinoma in Barrett's esophagus without grossly recognizable neoplastic lesions. Gastroenterology 1988;94:81-90.

41. Levine DS, Haggitt RC, Blount PL, et al. An endoscopic biopsy protocol can differentiate high-grade dysplasia from early adenocarcinoma in Barrett's esophagus. Gastroenterology 1993; 105:40-50.

42. Axon ATR, Boyle P, Riddell RH, et al. Summary of a working party on the surveillance of premalignant lesions. Am J Gastroenterol 1994;89:S160-8

43. Van Sandick JW, Van Lanschot JB, Kuiken BW, Tytgat GNJ, Offerhaus GJA, Obertop H. Impact of endoscopic biopsy surveillance of Barrett's esophagus on pathological stage and clinical outcome of Barrett's carcinoma. Gut 1998:43:216-22.

44. Lederle FA. Endoscopic surveillance of patients with Barrett esophagus. Ann Intern Med 1987;107:592-3.

45. Van Der Burgh A, Dees J, Hop WCJ, Van Blankenstein M. Oesophageal cancer is an uncommon cause of death in patients with Barrett's oesophagus. Gut 1996;39:5-8.

46. Wright TA, Gray MR, Morris AI, et al. Cost effectiveness of detecting Barrett's cancer. Gut 1996;39:574-9.

47. Streitz JM, Ellis FH, Tilden RL, Erickson RV. Endoscopic surveillance of Barrett's esophagus: a cost-effectiveness comparison with screening mammography. Am J Gastroenterol 1996;91:A71.

48. Spechler SJ, Goyal RK. Barrett's esophagus. N Engl J Med 1986;315:362-71.

49. Provenzale D, Kemp JA, Arora S, Wong JB. A guide for surveillance of patients with Barrett's esophagus. Am J Gastroenterol 1994;89:670-80.

50. Streitz JM Jr, Andrews CW Jr, Ellis FH Jr. Endoscopic surveillance of Barrett's esophagus. Does it help? J Thorac Cardiovasc Surg 1993;105:383-7.

51. Peters JH, Clark GW, Ireland AP, et al. Outcome of adenocarcinoma arising in Barrett's esophagus in endoscopically surveyed and nonsurveyed patients. J Thorac Cardiovasc Surg 1994;108:813-21.

52. Cole P, Morrison AS. Basic issues in population screening for cancer. J Natl Cancer Inst 1980;64:1263-72.

53. Hutchison GB, Shapiro S. Lead time gained by diagnostic screening for breast cancer. J Natl Cancer Inst 1968;41:665-81.

54. Zelen M. Theory of early detection of breast cancer in the general population. In: Henson JC, Mattheiem WH, Rozencweig M, eds. Breast Cancer: Trends in Research and Treatment. New York: Raven Press, 1976:287-300. 


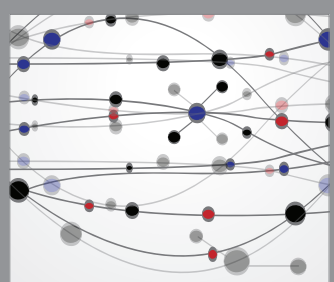

The Scientific World Journal
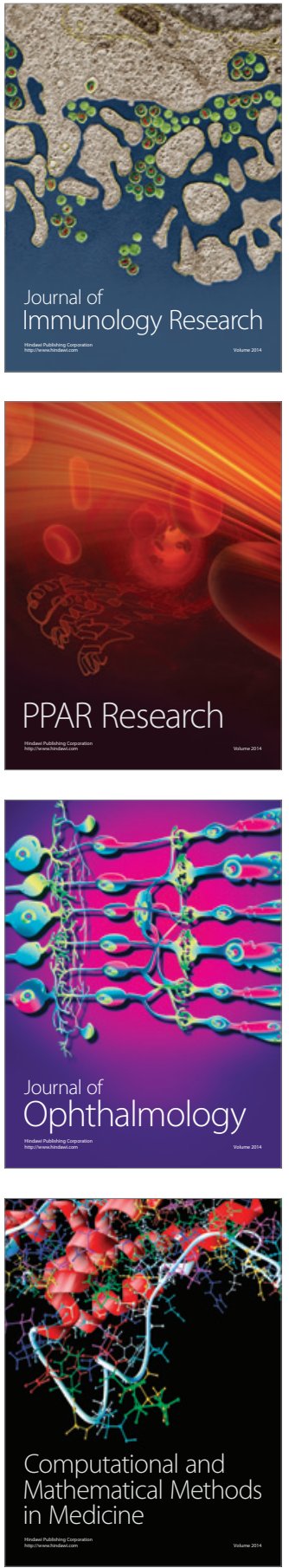

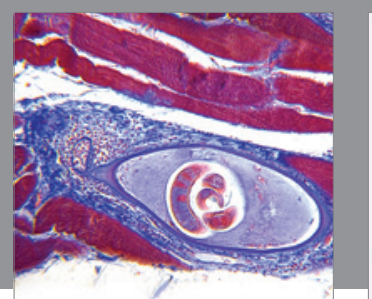

Gastroenterology Research and Practice

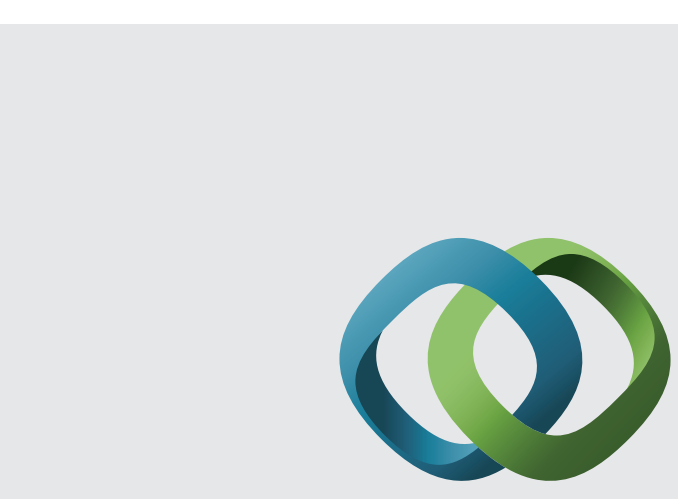

\section{Hindawi}

Submit your manuscripts at

http://www.hindawi.com
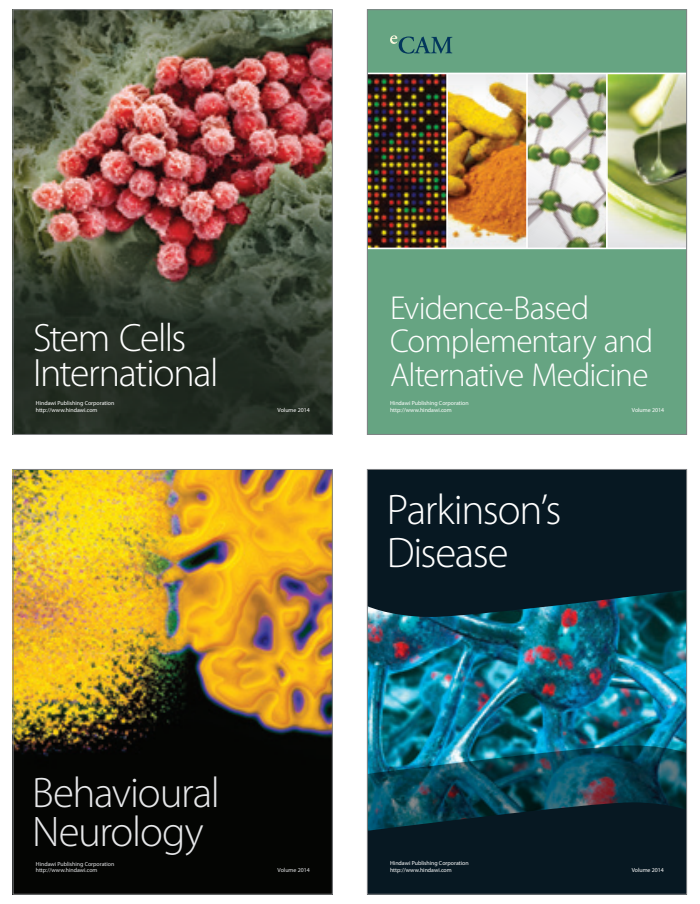
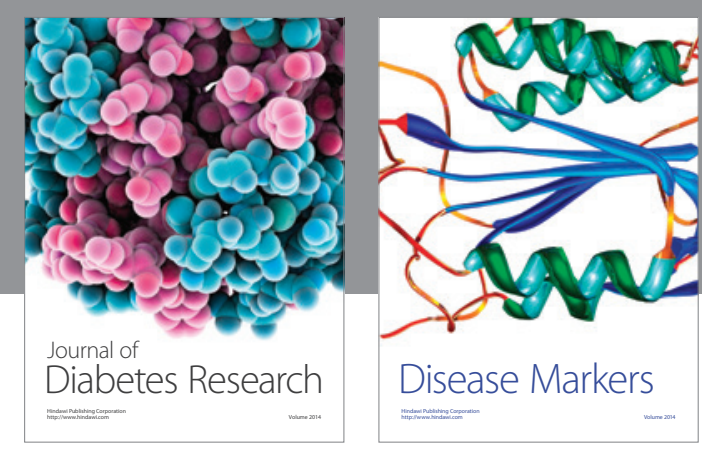

Disease Markers
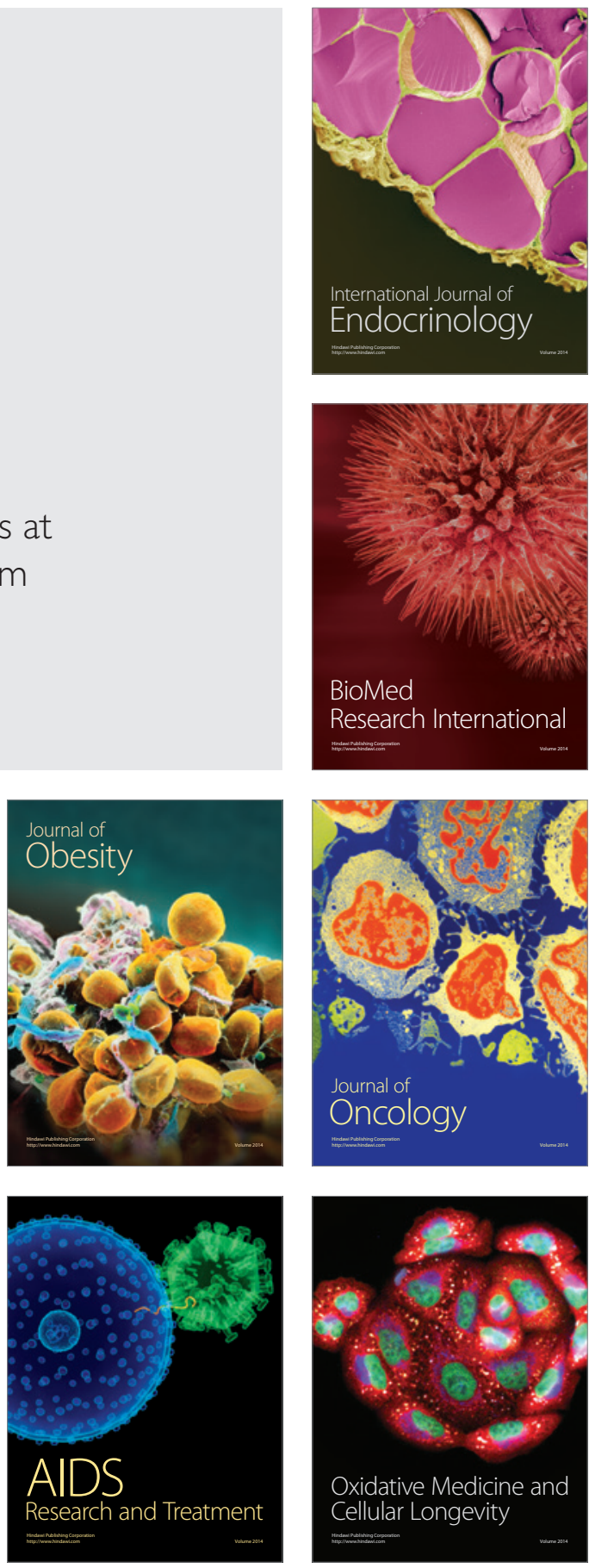